\title{
Quantificação de citocinas no soro e homogenato da pata na intoxicação experimental com veneno de Bothropoides jararaca em ratos Wistar tratados com soroterapia e Mikania glomerata
}

\author{
[Quantification of cytokines in serum and paw homogenate of experimental intoxication \\ for venom of the Bothropoides jararaca in Wistar rats treated with \\ antivenom and Mikania glomerata] \\ Y.P. Motta ${ }^{1}$, M. Sakate ${ }^{1}$, R.M.B. Nogueira ${ }^{2}$, M.T.S. Peraçoli ${ }^{3}$, F. Sangiorgio ${ }^{1}$, \\ R.S. Floriano ${ }^{2}$, E.N. Takahagi ${ }^{3}$ \\ ${ }^{1}$ Faculdade de Medicina Veterinária e Zootecnia - FMVZ-Unesp - Botucatu, SP \\ ${ }^{2}$ Faculdade de Ciências Agrárias - Unoeste - Presidente Prudente, SP \\ ${ }^{3}$ Instituto de Biociência de Botucatu - Unesp - Botucatu, SP
}

\begin{abstract}
RESUMO
O presente estudo teve como objetivo quantificar os níveis de citocinas pró-inflamatórias, entre as quais TNF- $\alpha$, interleucina-1 $\beta$ (IL-1 $\beta$ ), IL-6, e anti-inflamatórias, como IL-10, interferon- $\gamma$ (INF- $\gamma$ ), bem como comparar o efeito do tratamento convencional com o efeito do tratamento complementado pelo extrato da planta Mikania glomerata, na intoxicação experimental por Bothropoides jararaca. Foram usados ratos Wistar, divididos em três grupos: C - controle, VB - veneno botrópico + soro antiofídico e VBM veneno botrópico + soro antiofídico + Mikania glomerata. As citocinas foram quantificadas, no soro e no homogenato desses animais, pelo teste ELISA, em três momentos (M1 - 30 minutos, M2 - seis horas e M3 - 24 horas após a inoculação do veneno). Os resultados obtidos evidenciaram que a intoxicação por veneno botrópico estimula principalmente a produção de IL-6 no soro e TNF- $\alpha$, IL-1 $\beta$, IL-6 no homogenato da pata de animais experimentalmente intoxicados. $\mathrm{O}$ tratamento complementar, com o extrato da planta Mikania glomerata, teve influência principalmente na produção de IL-6, IL-10 e IFN- $\gamma$ no soro e IL-6, IL-1 $\beta$ e IFN- $\gamma$ no homogenato. Porém, são necessários novos estudos com o extrato de Mikania glomerata para que se possa entender a ação dessa planta sobre a intoxicação botrópica, bem como verificar qual a melhor via para administrá-lo.
\end{abstract}

Palavras-chaves: Bothropoides jararaca, Mikania glomerata, ratos Wistar, citocinas

\begin{abstract}
This experiment aimed to quantify the pro-inflammatory cytokine levels, including TNF- $\alpha$, interleukin-1 $\beta$ $(I L-1 \beta)$ and IL-6 as well as the anti-inflammatory ones such as IL-10 and INF- $\gamma$. It was also proposed to compare the effect of the conventional treatment to a treatment in which was added the Mikania glomerata plant in the experimental intoxication using Bothropoides jararaca venom. It was used Wistar rats that were randomly divided into 3 groups: $C$ - control; VB - Bothrops venom + antivenom serum; and VBM - Bothrops venom + antivenom serum + Mikania glomerata. Cytokines were quantified in the serum and paw homogenate using ELISA test in three different moments (M1-30 minutes, M2- 6 hours and M3- 24 hours after venom injection). The intoxication by Bothropoides jararaca venoms mainly stimulated the production of $I L-6$ in the serum and TNF- $\alpha, I L-1 \beta, I L-6$ in paw homogenate of animals experimentally intoxicated. Adjunctive treatment with the extract of the Mikania glomerata plant mainly influenced the production of IL-6, IL-10 and IFN- $\gamma$ in the serum and IL-6, ILI $\beta$ and-IFN- $\gamma$ in paw homogenate. Further research is necessary with the extract of Mikania glomerata in order to understand the action of this plant on the Bothropoides poisoning and also to verify the best way to manage it.
\end{abstract}

Keywords: Bothropoides jararaca; Mikania glomerata; Wistar rats; cytokine

Recebido em 6 de maio de 2013

Aceito em 19 de fevereiro de 2014

E-mail: yudney@gmail.com 


\section{INTRODUÇÃO}

Acidentes ofídicos representam um sério problema de saúde pública em países tropicais pela frequência com que ocorrem e pela morbimortalidade que ocasionam (Pinho e Pereira, 2001).

Dos quatros gêneros de serpentes peçonhentas de ocorrência no Brasil, verifica-se o predomínio do acidente botrópico, com $87,5 \%$ dos casos notificados no país, seguido pelo crotálico, 9,2\%, laquético, $2,7 \%$ e elapídico, $0,6 \%$, com pequenas variações de acordo com as diferentes regiões do país (Brasil, 2005).

O gênero Bothrops (jararaca, jararacuçu, urutu, caiçaca) representa o grupo mais importante de serpentes peçonhentas, com mais de 60 espécies encontradas em todo território brasileiro (incluindo os gêneros Bothriopsis, Bothrocophias, Bothropoides e Rhinocerophis) (Brasil, 2005; Wen et al., 2002; Fenwick et al., 2009). O veneno botrópico possui ações coagulante, proteolítica e vasculotóxica (Oliveira et al., 2003). É uma mistura complexa de metaloproteinases (toxinas hemorrágicas - jararagina), fosfolipase A2 (miotoxina), serinoproteases (enzimas tipo trombina) e peptídeos que agem sobre a bradicinina e o sistema angiotensina (Clissa, 2002).

As citocinas são polipeptídeos produzidos principalmente por linfócitos ativados e macrófagos, que modulam a função de outros tipos celulares. Estão envolvidas nas respostas imunológicas e apresentam efeitos importantes na resposta inflamatória. As principais mediadoras da inflamação são a interleucina 1 (IL-1), fator de necrose tumoral tipo alfa (TNF$\alpha$ ), e a interleucina 8 (IL-8). A liberação dessas citocinas pode ser estimulada por endotoxina, imunocomplexos, toxinas, trauma físico, entre outros processos. Exercem seus efeitos de três diferentes maneiras: atuando sobre a própria célula que as produz (efeito autócrino), sobre células vizinhas (efeito parácrino), ou em nível sistêmico (efeito endócrino). Suas principais células-alvo são as células endoteliais, os leucócitos e os fibroblastos. A IL-1, o TNF- $\alpha$ e a IL-6 estimulam respostas sistêmicas de fase aguda associadas à infecção ou à agressão e, assim, geram sinais clínicos, como febre e sedação, além de provocarem a liberação de neutrófilos, hormônio adrenocorticotrófico e corticosteroides para circulação (Contran, 2000). A IL-10 tem ação anti-inflamatória e é, portanto, capaz de diminuir a produção de IL-1 $\beta$, TNF- $\alpha$, IL-6 e IL-8 (Oswald et al., 1992; Bogdan et al., 1992).

A produção de citocinas tem sido descrita em modelos experimentais e em vítimas de acidentes botrópico e crotálico, porém poucas evidências sobre o envolvimento direto das citocinas na inflamação ocasionada pela intoxicação estão disponíveis na literatura (Lomonte et al., 1993; Barravieira et al., 1995; Barros et al., 1998 e Petricevich et al., 2000). Uma melhor compreensão da resposta inflamatória que ocorre nos acidentes ofídicos pode levar ao desenvolvimento de novas estratégias terapêuticas para auxiliar na recuperação desses pacientes (Ávila-Agüero et al., 2001).

O tratamento preconizado para neutralizar a ação do veneno botrópico é por meio da soroterapia. O soro bivalente antibotrópico-crotálico é o mais facilmente encontrado e utilizado em medicina veterinária. Mesmo sendo o tratamento recomendado, ainda apresenta algumas desvantagens, como: (1) limitado ou nenhum acesso ao soro antiofídico na zona rural de países em desenvolvimento, onde a maioria dos acidentes acontece; (2) variações significantes na composição do veneno e reatividade antigênica devido a diversidades de serpentes, o que pode causar limitações durante a soroterapia; (3) reações adversas em pacientes devido à infusão de proteínas equinas; e (4) efetividade limitada para proteger os efeitos deletérios no local da picada. Assim, a procura contínua e a identificação de novas combinações que possam ser úteis como terapia alternativa ou como terapias complementares para a intoxicação por veneno de serpente são tarefas pertinentes (Soares et al., 2005).

Em muitos países, extratos vegetais têm sido tradicionalmente utilizados no tratamento de acidentes ofídicos (Mors, 1991). O extrato de plantas com propriedades antiofídicas (Soares et al., 2004) é, muitas vezes, a única opção em comunidades sem acesso à soroterapia. Esses extratos constituem uma alternativa e, assim, exibem uma diversidade grande de combinações químicas com várias atividades farmacológicas 
de interesse médico-científico. A planta Mikania glomerata tem se mostrado eficaz na neutralização de muitos dos efeitos tóxicos do veneno botrópico (Maiorano et al., 2005), portanto, devido à alta incidência de acidentes ofídicos, desvantagens da soroterapia como único tratamento e a existência de poucos trabalhos sobre o efeito do tratamento da intoxicação botrópica com a planta Mikania glomerata sustentam a proposta do presente estudo em avaliar a produção de citocinas próinflamatórias e anti-inflamatórias na intoxicação experimental por veneno da serpente Bothropoides jararaca em ratos Wistar tratados com soro antiofídico e extrato de Mikania glomerata.

\section{MATERIAL E MÉTODOS}

O estudo foi aprovado previamente pela Comissão de Ética em Experimentação Animal CEUA da Faculdade de Medicina Veterinária e Zootecnia - Unesp/Botucatu (protocolo: 88/2006 - CEUA).

Foram utilizados 54 ratos Wistar, fêmeas, de dois meses de idade e peso corporal entre 230 e 300 gramas. Optou-se por usar fêmeas pela disponibilidade do biotério. Os animais foram mantidos em caixas de polipropileno com cinco animais em cada uma, no biotério de experimentação, em ambiente com fotoperíodo controlado (12 horas claro e 12 horas escuro) e temperatura constante $\left(25^{\circ} \mathrm{C}\right)$, umidade do ar de $55-65 \%$, tempo de exaustão de 12 trocas de ar da sala/hora, e receberam ração (Purina ${ }^{\circledR}$ ) e água $a d$ libitum. Os animais foram distribuídos em três grupos experimentais, com 18 animais por grupo, sendo: C - controle; VB - receberam $10 \mathrm{mg} / \mathrm{kg}$ de veneno botrópico + soro antiofídico (Vencofarma $^{\circledR}-$ dose recomendada pelo fabricante); VBM - receberam a mesma dose de veneno e soro do grupo VB + extrato de Mikania glomerata $10 \%$ no volume de $1 \mathrm{~mL}$, no intervalo de duas horas, com três repetições após a inoculação do veneno. Cada grupo foi avaliado em três momentos, sendo: M1 - 30 minutos após a inoculação do veneno; M2 - seis horas após a inoculação do veneno; e M3 - 24 horas após a inoculação do veneno.

Para cada momento, seis ratos foram anestesiados com tiopental sódico, na dose de
$100 \mathrm{mg} / \mathrm{kg}$, por via intraperitoneal, e o sangue foi coletado por meio de punção cardíaca, pela coleta a vácuo (Vacutainer Systems®). As amostras foram centrifugadas a 5000rpm durante 10 minutos, e os soros estocados a $-20^{\circ} \mathrm{C}$ para posterior dosagem das citocinas.

A musculatura da pata esquerda foi seccionada com auxílio de um punch com diâmetro de $8 \mathrm{~mm}$ e transferida para um tubo de reação $1,5 \mathrm{~mL}$ (eppendorf) contendo $200 \mathrm{~mL}$ de PBS. O tecido foi picotado com uma tesoura e posteriormente homogeneizado com uma haste de vidro. Após esse procedimento, a amostra foi centrifugada a 1200rpm durante seis minutos, e o sobrenadante congelado a $-20^{\circ} \mathrm{C}$ para posterior dosagem de citocinas.

Para a quantificação das citocinas no sobrenadante do homogenato da pata e do soro dos animais utilizados neste experimento, foi empregado o teste ELISA (Enzyme Linked Immuno Sorbent Assay), usando-se o kit comercial da R\&D Systems (Minneapolis, Minn, USA) de acordo com as instruções do fabricante.

Os resultados foram avaliados por análise de variância (ANOVA) para amostras dependentes, empregando-se o programa estatístico INSTAT, Graph Pad, San Diego, California, USA, 2000. O nível de significância adotado para os testes foi de $5 \%$.

\section{RESULTADOS E DISCUSSÃO}

As citocinas quando quantificadas no homogenato da pata, foi observado um aumento no TNF- $\alpha$; porém, não houve diferença estatística entre os tratamentos. Os animais intoxicados pelo veneno botrópico apresentam grande alteração no local da picada, o que é percebido quando esse local é avaliado por meio dos exames clínico e histopatológico, visto que podem ser encontradas alterações como necrose, congestão, hemorragia, edema e infiltração de células polimorfonucleares, as quais podem ocasionar maior liberação de citocinas próinflamatórias no local (Barraviera et al., 1995; Motta, 2009).

Com relação ao $\mathrm{TNF}-\alpha$, não houve alterações significantes na quantidade presente no soro, o que também foi observado em soro de pacientes humanos que sofreram picadas por serpentes 
Bothropoides jararaca, mesmo sendo comprovada a sua produção no local da picada (Lomente et al., 1993; Barraviera et al., 1995; Carneiro et al., 2002).

A IL-10 é uma citocina anti-inflamatória, e a sua produção por macrófagos e monócitos faz com que haja a diminuição de citocinas próinflamatórias (Oberholzer et al., 2002; RangelSantos et al., 2004). Sua liberação já foi observada em alguns trabalhos e em pacientes que sofreram intoxicação por veneno das serpentes Bothrops (Rangel-Santos et al., 2004), no entanto, neste estudo, não houve alterações significantes na produção de IL-10 quantificadas no soro e no homogenato. A produção de IL-10 é estimulada pelas citocinas pró-inflamatórias (IL1 e IFN), e a sua ausência pode ser devido ao tempo insuficiente para o estímulo da sua produção local (Rangel-Santos et al., 2004; Motta et al., 2009; Luna et al., 2011b).

O aumento da IL-6 no soro (Tab.1) após seis horas da inoculação está em conformidade com a literatura, que evidencia relatos desse aumento em pacientes ou animais de experimentação intoxicados com veneno botrópico (Lomente et al., 1993; Ávila-Aguero et al., 2001; Laing et al., 2003; Escocard et al., 2006; Luna et al., 2011a; Luna et al., 2011b). As citocinas quando quantificadas no homogenato, também houve um aumento da IL-6 após seis horas (Tab. 1) que se manteve até após 24 horas da inoculação. Esse resultado já era esperado, uma vez que o veneno botrópico causa um processo inflamatório intenso local (Barraviera et al., 1995; Motta, 2009).

Tabela 1. Valores médios e desvio-padrão $(\mathrm{M}(\mathrm{SD})$ ) de interleucina 6 (IL-6) no soro e no homogenato de ratos intoxicados com veneno botrópico tratados com soro antiofídico e Mikania glomerata $(\mathrm{pg} / \mathrm{mL})$, segundo grupos e momentos de avaliação

\begin{tabular}{cccl}
\hline Homogenato & $\mathrm{C}$ & $\mathrm{VB}$ & $\mathrm{VBM}$ \\
\hline 30 min. (M1) & $55,74(6,72) \mathrm{Ab}$ & $84,87(18,678) \mathrm{Ba}$ & $85,37(18,22) \mathrm{Ba}$ \\
6 horas (M2) & $56,37(2,15) \mathrm{Ab}$ & $1534,0(216,53) \mathrm{Aa}$ & $1298,6(268,12) \mathrm{Aa}$ \\
24 horas (M3) & $59,22(3,90) \mathrm{Ab}$ & $1680,0(515,65) \mathrm{Aa}$ & $1239,2(535,25) \mathrm{Aa}$ \\
\hline Soro & $\mathrm{C}$ & $\mathrm{VB}$ & $\mathrm{VBM}$ \\
\hline 30 minutos (M1) & $57,29(3,92) \mathrm{Aa}$ & $62,50(5,51) \mathrm{Ca}$ & $62,23(5,31) \mathrm{Ba}$ \\
6 horas (M2) & $56,94(2,88) \mathrm{Ab}$ & $81,01(5,57) \mathrm{Bb}$ & $208,06(106,90) \mathrm{Aa}$ \\
24 horas (M3) & $57,87(2,71) \mathrm{Ab}$ & $260,17(80,19) \mathrm{Aa}$ & $65,97(7,42) \mathrm{Bb}$ \\
\hline
\end{tabular}

Resultados: letras maiúsculas = coluna, comparam dentro do mesmo grupo; letras minúsculas = linha, comparam mesmo momento em grupos diferentes; e ( ) desvio- padrão.

Em comparação com o tratamento convencional, o soro antiofídico polivalente e o extrato aquoso de Mikania glomerata não foram capazes de reduzir a produção dessa citocina (IL-6) no local da inoculação, o que está de acordo com Motta (2008) e Soares et al. (2005), os quais relataram que a terapia sistêmica não provoca muitos efeitos benéficos para as alterações locais devido a alterações na circulação sanguínea no local da picada, fato que dificulta a ação dessa terapêutica.

O aumento dos níveis de IL-6, em resposta à inoculação do veneno, foi associado com o início da regeneração muscular. O efeito dessa citocina provoca migração de neutrófilos para os tecidos, ativa a maturação destes e regula moléculas de adesão das células endoteliais envolvidas na adesão de leucócitos ao endotélio (Suwa et al., 2002; Teixeira et al., 2009). No M3 do grupo que recebeu o tratamento complementar com o extrato da planta, foi observada a volta à normalidade da IL-6 quando este foi comparado ao grupo controle, o que pode estar relacionado com o potencial anti-inflamatório do extrato de Mikania glomerata (Maiorano et al., 2005; Motta et al., 2009).

O IFN- $\gamma$ é uma citocina pró-inflamatória, presente principalmente quando há lesão de músculo esquelético, a qual promove a regeneração das fibras musculares (Cheng et al., 2008). O grupo intoxicado com veneno botrópico e tratado com soro antiofídico e Mikania glomerata apresentou um aumento marcante do IFN- $\gamma$ no M24 após a inoculação do veneno, o que leva a acreditar que o extrato da planta aumenta a produção de IFN- $\gamma$ e que, portanto, é mais eficaz para a regeneração das fibras musculares após os acidentes por esses gêneros de serpentes (Tab. 2). 
Tabela 2. Valores médios e desvio-padrão de interferon-gama (IFN- $\gamma$ ) no soro de ratos intoxicados com veneno botrópico e tratados com soro antiofídico e Mikania glomerata (pg/mL), segundo grupos e momentos de avaliação

\begin{tabular}{cccc}
\hline Soro & C & VB & \multicolumn{1}{c}{ VBM } \\
\hline 30 min. (M1) & $20,39(4,23) \mathrm{Aa}$ & $24,08(3,64) \mathrm{Aa}$ & $24,08(3,640) \mathrm{Ba}$ \\
6 horas (M2) & $20,92(1,69) \mathrm{Aa}$ & $24,91(2,09) \mathrm{Aa}$ & $25,46(2,29) \mathrm{Ba}$ \\
24 horas (M3) & $24,47(2,34) \mathrm{Ab}$ & $31,25(3,50) \mathrm{Ab}$ & $121,77(9,64) \mathrm{Aa}$ \\
\hline
\end{tabular}

Resultados: letras maiúsculas = coluna, comparam dentro do mesmo grupo; letras minúsculas = linha, comparam mesmo momento em grupos diferentes; e ( ) desvio- padrão.

Motta (2009) e Floriano et al. (2009) observaram, por meio de exame histopatológico da musculatura do local da inoculação do veneno, redução da gravidade das lesões de animais tratados com o extrato de Mikania glomerata.

Os animais que foram intoxicados pelo veneno botrópico apresentaram um aumento da produção de IL-1 $\beta$ no local da inoculação, o que está relacionado com a ação proteolítica do veneno botrópico (Motta, 2009). Os animais que receberam o tratamento convencional apresentaram esse aumento seis horas (M2) e 24 horas (M3) após a inoculação, e os animais que receberam extrato de Mikania glomerata e soro antiofídico polivalente apresentaram um aumento estatisticamente significante apenas com 24 horas. Esse fato pode estar diretamente relacionado com a ação do extrato da planta, o qual já mostrou, em alguns estudos, ter um potencial anti-inflamatório que reduz a produção de IL-1 $\beta$, citocina pró-inflamatória responsável pela resposta aguda frente a uma agressão tecidual (Maiorano et al., 2005; Motta, 2009). Quando avaliado no soro, o aumento foi percebido após seis horas da inoculação, o que pode ser explicado pela inicial produção da IL$1 \beta$ no local da inoculação, a qual atinge, posteriormente, a corrente sanguínea, já que as ações vasculotóxica e proteolítica do veneno fazem com que ocorra um menor suporte sanguíneo no local da picada (Motta et al., 2009).

\section{CONCLUSÕES}

Conclui-se que a intoxicação pelo veneno botrópico estimula principalmente a produção de IL-6 no soro dos animais experimentalmente intoxicados. O tratamento complementar com o extrato da planta Mikania glomerata teve influência, sobretudo, na produção de IL-6, IL10 e IFN- $\gamma$. Em relação à produção local, o veneno botrópico estimula a produção de TNF- $\alpha$,
IL-1 $\beta$ e IL-6. São necessários novos estudos com o extrato de Mikania glomerata para entender a ação da planta como terapia complementar na intoxicação, bem como novos estudos sobre outras vias de administração.

\section{REFERÊNCIAS}

ÁVILA-AGÜERO, M.L.; PARÍS, M.M.; HU, S. et al. Systemic cytokine response in children bitten by snakes in Costa Rica. Pediatr. Emerg. Cary, v.17, p.425-429, 2001.

BARRAVIEIRA, B.; LOMONTE, B.; TARKKOWSKI, A. et al. Acute-phase reactions, including cytokines, in patients bitten by Bothrops and Crotalus snakes in Brazil. J. Venom. Anim. Toxins, v.1, p.1-11, 1995.

BARROS, S.F.; FRIEDLANSKAIA, I.; PETRICEVICH, V.L.; KIPNIS, T.L. Local inflammation, lethality and cytokine release in mice injected with Bothrops atrox venom. Mediat. Inflamm., v.7, p.339-346, 1998.

BOGDAN, C.; PAIK, J.; VODOVOTZ, Y.; NATHAN, C. Contrasting mechanisms for supression of macrophage cytokine release by transforming growth factor- $\beta$ and interleukin-10. J. Biol. Chem., v.32, p.23302-23308, 1992.

BRASIL. Secretaria de Vigilância em Saúde. Departamento de Vigilância Epidemiológica. Guia de Vigilância Epidemiológica. $6^{\mathrm{a}}$ edição. Brasília: Ministério da Saúde; 2005. 816p.

CARNEIRO, A.S.; RIBEIRO, O.R.; DE FRANCO, M. et al. Local inflammatory reaction induced by Bothrops jararaca venom differs in mice selected for acute inflammatory response. Toxicon, v.40, p.1571$1579,2002$.

CHENG, M.; NGUYEN, M.; FANTUZZI, G.; KOH, T.J. Endogenous interferon- $\gamma$ is required for efficient skeletal muscle regeneration. Am. J. Physiol. Cell. Physiol. v.294, p.1183-1191, 2008.

CLISSA, P.B. Caracterização do efeito da jararagina sobre a produção e liberação de citocinas próinflamatorias em modelo murino. 2002. 110f. Tese (Doutorado) - Instituto de Ciências Biomédicas, Universidade de São Paulo, São Paulo. 
CONTRAN, R.S. Patologia celular II: adaptações, acúmulos intracelulares e envelhecimento celular. In:__ ROBBINS. Patologia Estrutural $E$ Funcional. 5.ed, Rio de Janeiro : Guanabara-Koogan, 2000. p.37-38.

ESCOCARD, R.C.M.; KANASHIRO, M.M.; PETRETSKI, J.H. et al. Neutrophils regulate the expression of cytokines, chemokines and nitric oxide synthase/nitric oxide in mice injected with Bothrops atrox venom. Immunobiology, v.211, p.37-46, 2006

FENWICK A.M.; GUTBERLET Jr., R.L.; JENNAFER A. et al. Morphological and molecular evidence for phylogeny and classification of South American pitvipers, genera Bothrops, Bothriopsis, and Bothrocophias (Serpentes: Viperidae). Zool. J. Linn. Soc. v.156, p.617-640, 2009.

FLORIANO, R.S., NOGUEIRA, R. B., SAKATE, M., et al. Effect of Mikania glomerata leaf aqueous extract associated with anti-snake venom serum on experimental Crotalus durissus terrificus envenomation in rats. International Journal of Tropical Biology and Conservation, v. 57, p.929-937, 2009.

LAING, G.D.; CLISSA, P.B.; THEAKSTON, R.D. et al. Inflammatory pathogenesis of snake venom metalloproteinase-induced skin necrosis. Eur. $J$. Immunol., v.33, p.3458-3463, 2003.

LOMONTE, B.; TARKOWSKI, A.; HANSON, L.A. Host response to Bothrops asper snake venom. Analysis of oedema formation, inflammatory cells, and cytokine release in a mouse model. Inflammation, v.17, p.93-105, 1993.

LUNA, K.P.O.; DA SILVA, M.B.; PEREIRA, V.R.A. Clinical and immunological aspects of envenomations by Bothrops snakes. J. Venom. Anim. Toxins incl. Trop. Dis. v.17, p.130-141, 2011a.

LUNA, K.P.O.; MELO, C.M.L.; PASCOAL, V.P.M. et al. Bothrops erythromelas snake venom induces a proinflammatory response in mice splenocytes. Int. $J$. Interf. Cytok Mediator Res, v.3 p.9-18, $2011 \mathrm{~b}$.

MAIORANO, V.A.; MARCUSSI, S.; DAHER, M.A.F. et al. Antiophidian properties of the aqueous extract of Mikania glomerata. J. Ethnopharmacol., v.102, p.364-370, 2005.

MORS, W.B. Plants active against snake bite. Econ. Med. Plant Res., v.5, p.352-382, 1991.

MOTTA, Y.P.; SAKATE, M.; NOGUEIRA, R.M.B.; FLORIANO, R.S. et al. Avaliações clínica, laboratorial e histopatológica da intoxicação experimental por veneno da serpente Bothrops jararaca em ratos wistar e tratados com antiveneno e Mikania glomerata. Rev. Bras. Toxicol., v.22, p.217, 2009.
OBERHOLZER, A.; OBERHOLZER, C.; MOLDAWER, L.L. Interleukin 10: A complex role in the pathogenesis of sepsis syndromes and its potential as an antiinflamatory drugs. Crit. Care Med., v.30, p.58-63, 2002.

OLIVEIRA, R.B.; RIBEIRO, L.A.; JORGE. M.T. Fatores associados à incoagulabilidade sangüínea no envenenamento por serpentes do gênero Bothrops (Risk factors associated with coagulation abnormalities in Bothrops envenoming). Rev. Soc. Bras. Med. Trop. v.36, p.657-663, 2003.

OSWALD, I.P.; GAZZINELLI, R.T.; SHER, A.; JAMES, S.L IL-10 synergizes with IL-4 and transforming growth factor $\beta$ to inhibit macrophage cytotoxic activity. J. Immunol., v.148, p.3578-3582, 1992.

PETRICEVICH, V.L.; TEIXEIRA, C.F.; TAMBOURGI, D.V.; GUTIÉRREZ, J.M. Increments in serum cytokine and nitric oxide levels in mice injected with Bothrops asper and Bothrops jararaca snake venoms. Toxicon., v.38, p.1253-1266, 2000.

PINHO, F.M.O.; PEREIRA, I.D. Ofidismo. Rev. Assoc. Med. Bras., v.47, p.2-13, 2001.

RANGEL-SANTOS, A.; LIMA, A.; LOPESFERREIRA, M.; CARDOSO, D.F. Immunosuprresive role of principal toxin (crotoxin) of Crotalus durissus terrificus venom. Toxicon, v.44, p.609-616, 2004.

SOARES, A.M.; JANUÁRIO, A.H.; LOURENCO, M.V. et al. Neutralizing effects of Brazilian plants against snake venoms. Drug future, v.29, p.11051117,2004

SOARES A.M.; TICLI F.K.; MARCUSSI S. et al. Medicinal Plants with inhibitory properties against snake venoms. Curr. Med. Chem., v.12, p.2625-2641, 2005

SUWA, T.; HOGG, J.C.; QUINLAN, K.B.; VAN EEDEN, S.F. The effect of interleukin-6 on L-selectin levels on polymorphonuclear leukocytes. Am. J. Physiol. Heart Circ. Physiol., v.283, p.879-884, 2002.

TEIXEIRA, C.; CURY, Y.; MOREIRA, V. et al. Inflammation induced by Bothrops asper venom. Toxicon, v.54, p.988-997, 2009.

WEN, F.H.; CARDOSO, J.L.C.; MALAQUE, C.M.S. et al. Influências das alterações ambientais na epidemiologia dos acidentes ofídicos e na distribuição geográfica das serpentes de importância médica nos estados de São Paulo e Paraná, 1988-1997. Inf. Epidemiol. SUS, v.11, p.45-47, 2002. 